\title{
Atomic structure of $\mathrm{Cu}-\mathrm{Zr}$ - $\mathrm{Ti}$ metallic glasses subjected to high temperature annealing
}

J. Ďrišin ${ }^{\text {a }}$, D. Balga ${ }^{\mathrm{b}}, \mathrm{K}_{\text {. Saksl }}{ }^{\mathrm{b}}$, A. Pietriková ${ }^{\mathrm{a}}$

${ }^{a}$ Department of Technologies in Electronics, Faculty of Electrical Engineering and Informatics, Technical University of Košice, Letná 9, 04200 Košice, Slovak Republic

${ }^{\mathrm{b}}$ Institute of Materials Research, Slovak Academy of Sciences, Watsonova 47, 04001 Košice, Slovak Republic

Corresponding author (J. Ďurišin):

E-mail: juraj.durisin@tuke.sk. Tel.: +421 55602 3199. Fax: +421 556023195.

\begin{abstract}
An influence of high temperature annealing process (before crystallization) on the atomic structure of two different as-prepared ribbon $\mathrm{Cu}-\mathrm{Zr}-\mathrm{Ti}$ metallic glasses $\left(\mathrm{Cu}_{60} \mathrm{Zr}_{20} \mathrm{Ti}_{20}\right.$ and $\mathrm{Cu}_{55} \mathrm{Zr}_{16} \mathrm{Ti}_{29}$, at. \%) was experimentally studied by means of differential scanning calorimetry and in situ hard X-ray diffraction. Results of our experiments prove different atomic structure and behaviour of the glasses upon the annealing. Special emphasis is placed on the thermally activated effects which precede the crystallization. During the annealing, both glasses initially show with elevated temperature continuous short and middle range order thermal expansion and an overall decline of the atomic structure ordering. But above a temperature, which can be slightly different for every mean atomic neighbour (or every atomic coordination shell), one can observe a change in behaviour of the glasses: the glasses modify the thermal expansion rate of most of the mean atomic neighbours' distances and show a tendency to increase the degree of ordering of the atomic structure. Both these effects are more pronounced for $\mathrm{Cu}_{55} \mathrm{Zr}_{16} \mathrm{Ti}_{29}$. Therefore, as a result of the metallic glasses' different behaviour in the annealing, near the crystallization temperature $\mathrm{Cu}_{55} \mathrm{Zr}_{16} \mathrm{Ti}_{29}$ commonly shows larger relative elongation of the mean atomic neighbours' distances (larger thermal expansion) than $\mathrm{Cu}_{60} \mathrm{Zr}_{20} \mathrm{Ti}_{20}$. Moreover, $\mathrm{Cu}_{55} \mathrm{Zr}_{16} \mathrm{Ti}_{29}$ exhibits contrary to $\mathrm{Cu}_{60} \mathrm{Zr}_{20} \mathrm{Ti}_{20}$ an increase of the degree of ordering of the atomic structure if compared with the initial as-prepared state at the beginning of the experiment.
\end{abstract}

Keywords: Metallic glass; Differential scanning calorimetry; Hard X-ray diffraction; Atomic structure; Mean atomic neighbour 


\section{Introduction}

Metallic glasses based on $\mathrm{Cu}$ are today extensively used for various applications due to their high corrosion resistance and extraordinary high strength coupled with great ductility at room temperature (up to $18 \%$ ) [1]. Great ductility, which is uncommon for the vast majority of metallic glasses, predetermines $\mathrm{Cu}$-based glasses for applications where deformation can be converted into measurable units such as fluid flow rate or electric signals and in this way they can be applied for different kinds of construction materials or sensors. High potential is shown especially by ternary $\mathrm{Cu}-\mathrm{Zr}-\mathrm{Ti}$ glassy alloys, which exhibit extraordinary mechanical properties: tensile fracture strength of approximately $2100 \mathrm{MPa}$ and a compressive plastic strain in the range of $0.8-1.7 \%$. These amorphous alloys show also minimal corrosion rates in various environments $[2,3]$. Many investigations on $\mathrm{Cu}-\mathrm{Zr}-\mathrm{Ti}$ glassy alloys have been done so far, in particular on alloys with high $\mathrm{Cu}$ content. Pauly et al. [4] have focused on the phase formation and the thermal stability of $\mathrm{Cu}_{50} \mathrm{Zr}_{50-\mathrm{x}} \mathrm{Ti}_{\mathrm{x}}(0 \leq \mathrm{x} \leq 10)$ systems. Louzguine and Inoue [5] have proved that metastable $\mathrm{Cu}-\mathrm{Zr}-\mathrm{Ti}$ cubic phases primarily precipitate in $\mathrm{Cu}_{60} \mathrm{Zr}_{30} \mathrm{Ti}_{10}$ and that the metallic glass crystallizes with low energy barrier for nucleation. Kasai et al. [6] have studied structure and crystallization of rapidly quenched $\mathrm{Cu}_{60} \mathrm{Zr}_{30} \mathrm{Ti}_{10}$ alloy containing nanocrystalline particles and it has been demonstrated that the $\mathrm{Cu}$ element enriched nanocrystalline phases of the cubic structure are observed in the glassy matrix. The kinetics of an amorphous-to- $\mathrm{Cu}_{51} \mathrm{Zr}_{14}$ phase transformation in an as-cast $\mathrm{Cu}_{60} \mathrm{Ti}_{20} \mathrm{Zr}_{20}$ rod has been investigated by differential scanning calorimetry [7]. Concustell et al. [8] have analysed microstructural evolution during decomposition and crystallization of the $\mathrm{Cu}_{60} \mathrm{Zr}_{20} \mathrm{Ti}_{20}$ amorphous alloy and among all else they have discovered, that the alloy exhibits two exothermic crystallization stages resulting in two different hexagonal crystalline phases. Composition design and mechanical properties of ternary $\mathrm{Cu}-\mathrm{Zr}-\mathrm{Ti}$ bulk metallic glasses (BMGs) have been studied by Pan et al. [9]; the results show that the designed alloys possess good glass forming ability and excellent mechanical properties. Formation of BMGs in the $\mathrm{Cu}$-rich $\mathrm{Cu}-\mathrm{Zr}-\mathrm{Ti}$ ternary system has been researched by Wang et al. [10]; the BMGs on each composition line manifest decreased thermal stabilities and glass forming abilities with increasing Ti content. Dai et al. [11] have found a new composition zone of BMGs formation (around $\mathrm{Cu}_{52} \mathrm{Zr}_{40} \mathrm{Ti}_{8}$ ) in the $\mathrm{Cu}-\mathrm{Zr}-\mathrm{Ti}$ ternary system. Cai et al. have revealed, that the structural sensitivity of $\mathrm{Cu}-\mathrm{Zr}-\mathrm{Ti}$ amorphous alloys to compression [12] and tension [13] decreases with increasing $\mathrm{Cu}$ content. Expansion of the amorphous phase causing larger inter- 
atomic distances has been observed with increasing $\mathrm{Sn}$ content in $\left(\mathrm{Cu}_{60} \mathrm{Zr}_{25} \mathrm{Ti}_{15}\right)_{100-\mathrm{x}} \mathrm{Sn}_{\mathrm{x}}$ alloys ( $\mathrm{x}=0,1,2,3$ and 4) [14]. Enhancement of solderability of $\mathrm{Cu}_{60} \mathrm{Zr}_{30} \mathrm{Ti}_{10}$ BMG has been achieved by Naoi et al. [15] and its dealloying behavior has been analysed under free corrosion conditions [16] resulting in the idea, that dealloying metallic glasses may be a possible candidate for developing nanostructured metals. Moreover, Basu et al. [17] have shown that Miedema's approach has been useful in determining the glass forming composition range for a particular alloy system (including the $\mathrm{Cu}-\mathrm{Zr}-\mathrm{Ti}$ system). But until today, nobody has reported how the atomic structure of this particular ternary amorphous system changes upon annealing. And this is exactly goal of our work.

By classical statistical mechanics, the atomic structure of metallic glasses can be described in reciprocal space by means of the structure factor and in real space by the reduced pair distribution function or the pair distribution function reflecting pairwise interatomic interactions of the constituent atoms. Unlike in crystalline solid metals, where the long range order is determined by periodic assembling of the unit cells, metallic glasses exhibit only the short and middle range order.

In this article we present modifications of the atomic structure of $\mathrm{Cu}_{60} \mathrm{Zr}_{20} \mathrm{Ti}_{20}$ and $\mathrm{Cu}_{55} \mathrm{Zr}_{16} \mathrm{Ti}_{29}$ (at. \%) metallic glass upon annealing at high temperature. Our study is based on analysis of the reduced pair distribution function $G(r)$ obtained from X-ray diffraction patterns taken at different, gradually increased temperature (in situ type of experiment). Since there are many studies devoted to the crystallization of $\mathrm{Cu}-\mathrm{Zr}-\mathrm{Ti}$ ternary alloys, we restrict ourselves in this paper to the atomic structure in the temperature region starting from room temperature and ending near the first crystallization. We believe that the comparative investigation of the two different metallic glasses by in situ hard X-ray diffraction (XRD) contributes to better understanding of ternary glasses based on $\mathrm{Cu}, \mathrm{Zr}$ and $\mathrm{Ti}$. In order to reveal small structure modifications of the highly disordered systems we have decided to perform our experiments at the highly intense X-ray source (DORIS III synchrotron radiation source) located at DESY in Hamburg, Germany. Measurements performed with high intensity and high energy X-ray photons allow irradiating relatively large volume of samples (several $\mathrm{mm}^{3}$ ) and enable the collecting of in situ high quality two-dimensional (2D) XRD patterns in sub-minute time resolution as well. 


\section{Materials and methods}

Samples of the metallic glasses $\left(\mathrm{Cu}_{60} \mathrm{Zr}_{20} \mathrm{Ti}_{20}\right.$ and $\left.\mathrm{Cu}_{55} \mathrm{Zr}_{16} \mathrm{Ti}_{29}\right)$ with a thickness of $40 \mu \mathrm{m}$ were prepared from arc melted master alloys by single-roller melt spinning in the Laboratory of New-Structured Materials, Department of Materials Science and Engineering, Zhejiang University, China.

A differential scanning calorimeter (Perkin Elmer DSC 8000) was used to detect thermally induced phase transitions of the glasses at a heating rate of $10 \mathrm{~K} \mathrm{~min}^{-1}$.

Chemical composition of the glassy alloys was verified by energy dispersive X-ray microanalysis (EDX) installed in a field emission scanning electron microscope JEOL JSM-7000F.

The hard XRD measurements were carried out in transmission (Debye-Scherrer) geometry at the BW5 wiggler beamline [18] at the positron storage ring DORIS III located at DESY in Hamburg, Germany (energy of a positron $4.45 \mathrm{GeV}$, positron current between $100 \mathrm{~mA}$ and 140 $\mathrm{mA})$. The experiments were realized by using monochromatized X-ray radiation of wavelength $0.124 \AA$ corresponding to a photon energy of $100 \mathrm{keV}$. The highly collimated X-ray beam with cross sectional area $0.5 \mathrm{~mm} \times 0.5 \mathrm{~mm}$ illuminated ribbon samples of the metallic glasses while diffracted X-rays were recorded by a 2D image plate detector Perkin Elmer XRD 1621 (2048 pixels $\times 2048$ pixels, size of a pixel: $200 \mu \mathrm{m} \times 200 \mu \mathrm{m}$ ) [19]. By this setup we were able to collect high quality 2D XRD patterns up to the magnitude of the scattering vector $Q_{\max }=4 \pi \sin (\theta) / \lambda=18 \AA^{-1}$, where $\theta$ is half of the scattering angle and $\lambda$ is X-ray wavelength. $Q_{\max }$ also determines resolution in real space to be $\Delta r=\pi / Q_{\max }=0.1745 \AA$ [20]. During the experiments $\mathrm{Cu}_{60} \mathrm{Zr}_{20} \mathrm{Ti}_{20}$ and $\mathrm{Cu}_{55} \mathrm{Zr}_{16} \mathrm{Ti}_{29}$ amorphous ribbons were cut into small pieces and put into a quartz capillary of inner diameter of $0.8 \mathrm{~mm}$. The capillary was mounted into a Linkam THMS600 resistive heater furnace with a maximal operating temperature of $873 \mathrm{~K}$ and thermal stability better than $1 \mathrm{~K}$ [21]. The temperature in the samples' vicinity was measured by a thermocouple. The samples were heated up from room temperature up to their crystallization point by $10 \mathrm{~K}$ $\min ^{-1}$ heating rate. After reaching the required temperature, the glasses were illuminated by the X-ray beam for $20 \mathrm{~s}$ and 2D XRD patterns were recorded by the detector. Additionally, a time of about $15 \mathrm{~s}$ was needed for data transfer from the detector to a computer, to relax the detector and to stabilize the temperature. 
The measured 2D patterns of XRD intensity were radially integrated from 2D space to $1 \mathrm{D}$ space $(I(Q)$, intensity vs. $Q)$ by using the fit2D software [22]. The total structure factors $S(Q)$ 's were derived from $I(Q)$ 's by application of standard methods, as described e.g. in [23,24,25,26], where the $I(Q)$ patterns were corrected for amount of the scattering sample/time of a measurement/time decay of the positron current in the positron storage ring DORIS III (all these factors can be represented by one single scale factor), scattering power of the constituent elements (X-ray atom form factor of $\mathrm{Cu}, \mathrm{Zr}$ and $\mathrm{Ti}$ ), polarization of the incident primary $\mathrm{X}$-ray beam, absorption of the sample, multiple scattering (second order), Laue diffuse scattering, Compton inelastic scattering, isotropic fluorescence (assumed to be constant in the entire $Q$ range), background and capillary signal. $S(Q)$ 's from the measured $I(Q)$ 's were done using the PDFgetX2 software [27]. To normalize the measured data on an absolute scale, we applied the so-called high $Q$ method.

The total structure factor $S(Q)$ was calculated from $I_{e}(Q)$, i.e. the elastically scattered $\mathrm{X}$-ray signal by using Faber-Ziman formalism [28]

$$
S(Q)=1+\frac{I_{e}(Q)-\sum_{i=1}^{N} c_{i} f_{i}^{2}(Q)}{\left[\sum_{i=1}^{N} c_{i} f_{i}(Q)\right]^{2}},
$$

where $c_{i}$ and $f_{i}(Q)$ are the atomic concentration and the X-ray atom form factor of the atomic species of type $i(i=\mathrm{Cu}, \mathrm{Zr}$ or $\mathrm{Ti})$, respectively. $S(Q)$ can be written in the form

$$
S(Q)=\sum_{i, j}^{N} w_{i j}(Q) S_{i j}(Q),
$$

where $S_{i j}(Q)$ represents the partial structure factor and $w_{i j}$ is the weight of $i$-j pair, calculated as follows:

$$
\begin{aligned}
& w_{i j}=\frac{2 c_{i} f_{i}(Q) c_{j} f_{j}(Q)}{\left[\sum_{k=1}^{N} c_{k} f_{k}(Q)\right]^{2}} i=j, \\
& w_{i j}=\frac{c_{i}^{2} f_{i}^{2}(Q)}{\left[\sum_{k=1}^{N} c_{k} f_{k}(Q)\right]^{2}} i \neq j .
\end{aligned}
$$


The reduced pair distribution function, $G(r)$, was obtained by a Fourier sine transform of $S(Q)$ $[25,26]$

$G(r)=\frac{2}{\pi} \int_{0}^{Q_{\max }} Q[S(Q)-1] \sin (r Q) d Q=4 \pi r\left[\rho(r)-\rho_{0}\right]=4 \pi r \rho_{0}[g(r)-1]$,

where $\rho(r)$ and $\rho_{0}$ are the pair density function and the average number density, respectively, $g(r)$ is the pair distribution function and $r$ is the radial distance from the centre of an atom in the sample.

\section{Results and discussion}

\subsection{Differential scanning calorimetry and EDX analysis}

By applying differential scanning calorimetry (DSC) we determined the glass transition temperature $T_{g}$ and the onset temperature $T_{x o}$ of the first crystallization for the investigated glassy alloys (Fig. 1). For $\mathrm{Cu}_{60} \mathrm{Zr}_{20} \mathrm{Ti}_{20} T_{g}$ is $695 \mathrm{~K}$ and $T_{x o}$ is $732 \mathrm{~K}$; for $\mathrm{Cu}_{55} \mathrm{Zr}_{16} \mathrm{Ti}_{29} T_{g}$ is $687 \mathrm{~K}$ and $T_{x o}$ is $706 \mathrm{~K}$. The EDX microanalysis of the alloys proved indeed the chemical composition declared by the producer. For $\mathrm{Cu}_{60} \mathrm{Zr}_{20} \mathrm{Ti}_{20}$ alloy we obtained 57.65 at. $\% \mathrm{Cu}, 22.64$ at. $\% \mathrm{Zr}$ and 19.71 at. $\% \mathrm{Ti}$; for $\mathrm{Cu}_{55} \mathrm{Zr}_{16} \mathrm{Ti}_{29}$ alloy we obtained 53.40 at. $\% \mathrm{Cu}, 18.18$ at. $\% \mathrm{Zr}$ and 28.42 at. $\% \mathrm{Ti}$.

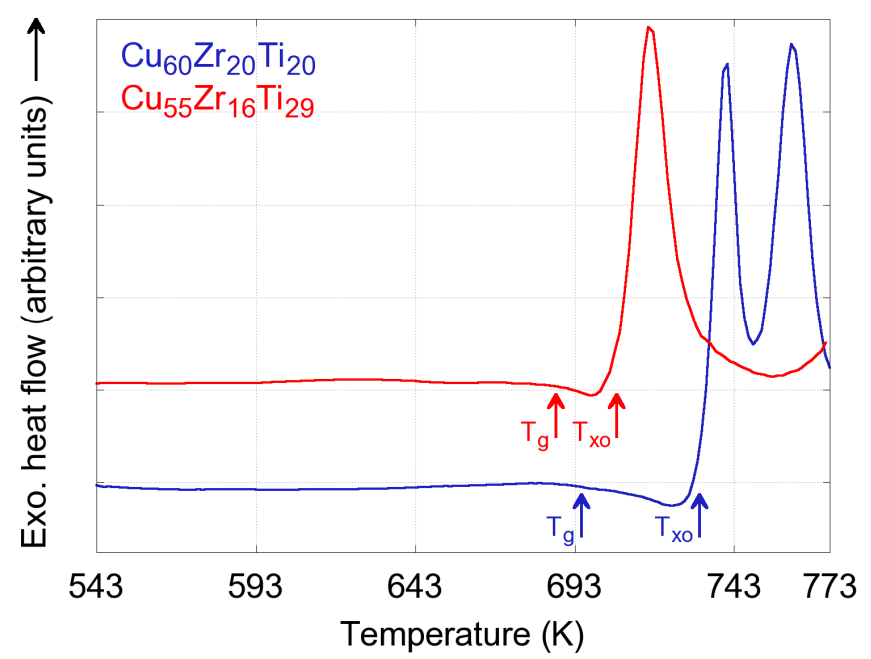

Fig. 1. (Colour online) DSC curves of $\mathrm{Cu}_{60} \mathrm{Zr}_{20} \mathrm{Ti}_{20}$ and $\mathrm{Cu}_{55} \mathrm{Zr}_{16} \mathrm{Ti}_{29}$ metallic glass shown in the temperature range of 543-773 $\mathrm{K}$. 


\subsection{Reciprocal space analysis}

The total structure factors $S(Q)$ 's of $\mathrm{Cu}_{60} \mathrm{Zr}_{20} \mathrm{Ti}_{20}$ and $\mathrm{Cu}_{55} \mathrm{Zr}_{16} \mathrm{Ti}_{29}$ metallic glass measured at $303 \mathrm{~K}$ are shown in Fig. 2. Both $S(Q)$ 's show a pronounced first peak, broad and split second peak (with a shoulder on its right side) followed by strongly damping oscillations being visible up to $16 \AA^{-1}$. For $\mathrm{Cu}_{60} \mathrm{Zr}_{20} \mathrm{Ti}_{20}$ the first peak maximum is located at $2.8567 \AA^{-1}$ and for $\mathrm{Cu}_{55} \mathrm{Zr}_{16} \mathrm{Ti}_{29}$ at $2.8548 \AA^{-1}$. The most evident differences between $S(Q)$ 's are: position and amplitude of the first $S(Q)$ peak maximum (the inset in Fig. 2), pre-peak visible at $\sim 1.5 \AA^{-1}$ for $\mathrm{Cu}_{55} \mathrm{Zr}_{16} \mathrm{Ti}_{29}$ and dephasing of $S(Q)$ 's oscillations above $\sim 6.94 \AA^{-1}$. But both $S(Q)$ courses are very similar, indicating also very similar atomic structure of these alloys.

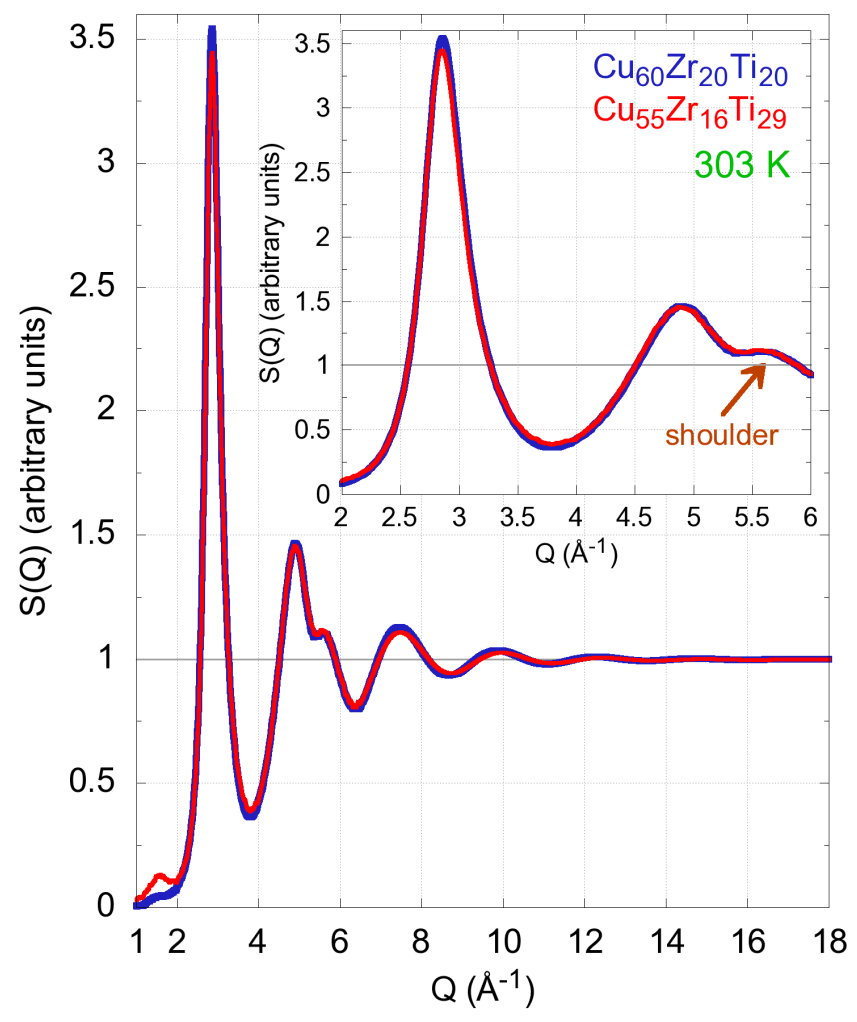

Fig. 2. (Colour online) The total structure factors $S(Q)$ 's of $\mathrm{Cu}_{60} \mathrm{Zr}_{20} \mathrm{Ti}_{20}$ and $\mathrm{Cu}_{55} \mathrm{Zr}_{16} \mathrm{Ti}_{29}$ metallic glass shown at $303 \mathrm{~K}$ in the $Q$ region of 1-18 $\AA^{-1}$. The inset shows $S(Q)$ 's in the $Q$ region of 2-6 $\AA^{-1}$.

During the annealing we obtained a series of relatively similar $S(Q)$ patterns to those measured at $303 \mathrm{~K}$. However, with increased temperature the position of the first peak maximum for the two glasses moves to the left - towards lower $Q$ values (the glasses thermally expand) and its amplitude decreases as a consequence of increased atomic thermal motion. In order to quantify 
temperature influence on the first peak maximum position $\left(P_{T}\right)$ and amplitude $\left(A_{T}\right)$ we analysed relative changes of these parameters; the parameters were normalized to the values $\left(P_{303}, A_{303}\right)$ measured near room temperature ( $303 \mathrm{~K})$ by taking them as reference or normalization constants. The results are shown in Fig. 3.

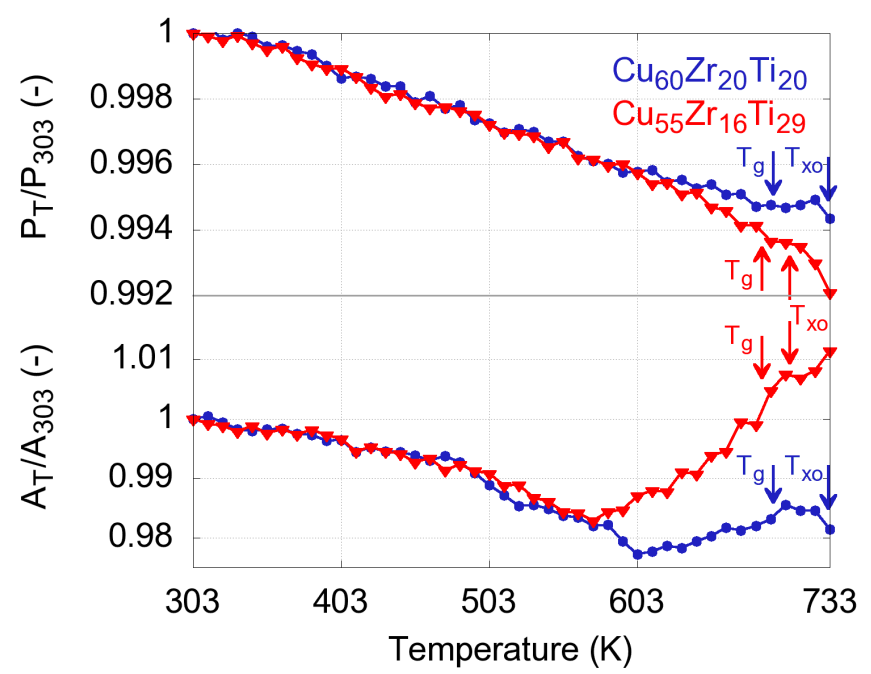

Fig. 3. (Colour online) Relative positions $\left(P_{T} / P_{303}\right)$ and relative amplitudes $\left(A_{T} / A_{303}\right)$ for the first $S(Q)$ peak maximum of $\mathrm{Cu}_{60} \mathrm{Zr}_{20} \mathrm{Ti}_{20}$ and $\mathrm{Cu}_{55} \mathrm{Zr}_{16} \mathrm{Ti}_{29}$ metallic glass during the annealing process (shown up to $733 \mathrm{~K}$ ). The full lines are guides for the eyes. Absolute values for $\mathrm{Cu}_{60} \mathrm{Zr}_{20} \mathrm{Ti}_{20}$ at $303 \mathrm{~K}: P_{303}=2.8567 \AA^{-1}$, $A_{303}=3.5538$. Absolute values for $\mathrm{Cu}_{55} \mathrm{Zr}_{16} \mathrm{Ti}_{29}$ at $303 \mathrm{~K}: P_{303}=2.8548 \AA^{-1}, A_{303}=3.4612$.

The relative position (parameter $P_{T} / P_{303}$ ) of the first $S(Q)$ peak maximum decreases between 303-603 K for both glasses more or less linearly and almost identically with an average slope $-1.415 \times 10^{-5} \mathrm{~K}^{-1}$, but from $603 \mathrm{~K}$ (far before $T_{g}$ ) $P_{T} / P_{303}$ begins to deviate from its precedent course. For $\mathrm{Cu}_{60} \mathrm{Zr}_{20} \mathrm{Ti}_{20}, P_{T} / P_{303}$ continues in a slightly modified decrease trend up to $683 \mathrm{~K}$; between $683 \mathrm{~K}$ and $T_{x o}$ one can observe a gentle increase tendency. For $\mathrm{Cu}_{55} \mathrm{Zr}_{16} \mathrm{Ti}_{29}$, above 603 $\mathrm{K} P_{T} / P_{303}$ clearly follows a different course than $\mathrm{Cu}_{60} \mathrm{Zr}_{20} \mathrm{Ti}_{20}$ and decreases up to $T_{x o}$ almost linearly and steeper than previously below $603 \mathrm{~K}$. Thus, comparison of final values of $P_{T} / P_{303}$ near the corresponding $T_{x o}$ brought us to the conclusion that $\mathrm{Cu}_{55} \mathrm{Zr}_{16} \mathrm{Ti}_{29}\left(P_{T x o} / P_{303}=0.9936\right)$ upon the annealing undergoes more intense changes of the mean atomic neighbours' distances than $\mathrm{Cu}_{60} \mathrm{Zr}_{20} \mathrm{Ti}_{20}\left(P_{T x o} / P_{303}=0.9949\right)$.

The relative amplitude (parameter $A_{T} / A_{303}$ ) of the first $S(Q)$ peak maximum shows between $303-573 \mathrm{~K}$ similar decrease path for both glasses (with an average slope $-6.525 \times 10^{-5} \mathrm{~K}^{-1}$ ) and after $573 \mathrm{~K} A_{T} / A_{303}$ courses diverge from each other. For $\mathrm{Cu}_{55} \mathrm{Zr}_{16} \mathrm{Ti}_{29}$ there is an evident rising 
tendency of $A_{T} / A_{303}$ up to $T_{x o}$. Analogously, for $\mathrm{Cu}_{60} \mathrm{Zr}_{20} \mathrm{Ti}_{20}$, its relative amplitude also increases, but here above $603 \mathrm{~K}$ and with a clearly lower slope than for $\mathrm{Cu}_{55} \mathrm{Zr}_{16} \mathrm{Ti}_{29}$ glass; then above 703 $\mathrm{K} A_{T} / A_{303}$ drops down. If one compares $A_{T} / A_{303}$ of the metallic glasses near the corresponding $T_{x o}$, $\mathrm{Cu}_{55} \mathrm{Zr}_{16} \mathrm{Ti}_{29}\left(A_{T x o} / A_{303}=1.00754\right)$ exhibits close to the crystallization a significantly higher degree of ordering of its atomic structure (especially towards higher $r$ ) than at the initial as-prepared state at the beginning of the experiment. Hence, the overall growth of $A_{T} / A_{303}$ for $\mathrm{Cu}_{55} \mathrm{Zr}_{16} \mathrm{Ti}_{29}$ alloy can be attributed to better ordering of atoms - effect of higher diffusion rate of atoms caused by elevated temperature. The better ordering means larger atomic population at certain sites resulting in stronger X-ray scattering. The ordering effect competes with the atomic thermal motion; the motion causes displacement of atoms from their mean positions, but obviously here the ordering effect prevails.

The pre-peak at $\sim 1.5 \AA^{-1}$ in the case of $\mathrm{Cu}_{55} \mathrm{Zr}_{16} \mathrm{Ti}_{29}$ (Fig. 2) characterizes the middle range order [29]. The pre-peak tends to move with temperature towards lower $Q$. Its amplitude initially considerably decreases but above $623 \mathrm{~K}$ the amplitude rises up to $T_{x o}$; the pre-peak shows behaviour similar to the first $S(Q)$ peak. The physical origin of a pre-peak is generally assigned to a compound forming behaviour (relative to the strong chemical bonds causing intermetallic compounds formation) [30] or it can be assigned to a cluster structure formed from different atoms [31].

Similar to the first $S(Q)$ peak, the second and the following $S(Q)$ peaks modify their position and amplitude in accordance with modification of the structure of the glasses.

Our observations in reciprocal space can be summarized in the following way: the glassy alloys start to relax their atomic structure far below $T_{g}$ (approximately $100 \mathrm{~K}$ below $T_{g}$ ). Their atomic structure tends to increase its ordering with temperature, but the glasses are still amorphous at least in the long range order. The ordering tendency is more pronounced in the case of $\mathrm{Cu}_{55} \mathrm{Zr}_{16} \mathrm{Ti}_{29}$ which possesses higher atomic mobility compared to $\mathrm{Cu}_{60} \mathrm{Zr}_{20} \mathrm{Ti}_{20}$.

\subsection{Real space analysis}

In order to analyse structural changes of the metallic glasses in more depth and in a more comprehensible way, we acceded to real space analysis by evaluating the reduced pair distribution functions $G(r)$ 's calculated from the corresponding $S(Q)$ 's. $G(r)$ 's of $\mathrm{Cu}_{60} \mathrm{Zr}_{20} \mathrm{Ti}_{20}$ and $\mathrm{Cu}_{55} \mathrm{Zr}_{16} \mathrm{Ti}_{29}$ sample (calculated up to $20 \AA$ from the $S(Q)$ patterns depicted in Fig. 2) are shown 
in Fig. 4. Enlarged is the first peak of $G(r)$ 's (the inset in Fig. 4) representing the first atomic coordination shell in real space ( $r$ range of 2.2-3.7 $\AA$ ).

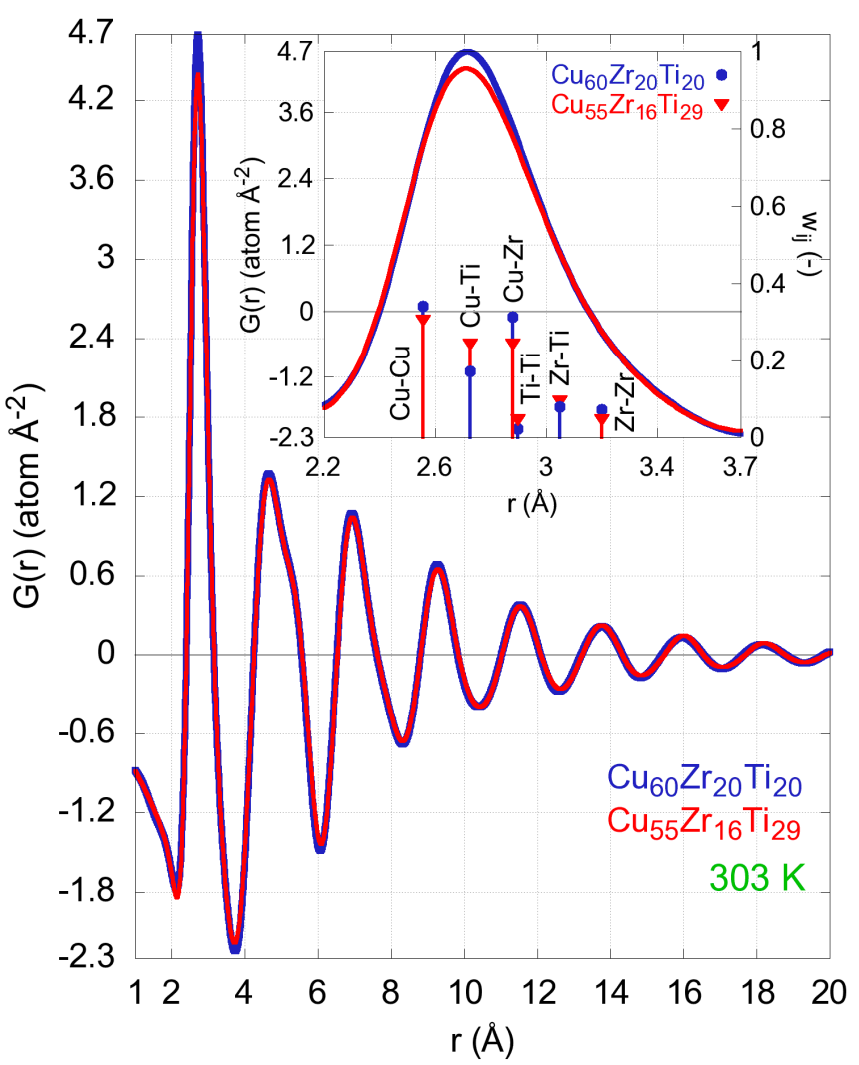

Fig. 4. (Colour online) The reduced pair distribution functions $G(r)$ 's of $\mathrm{Cu}_{60} \mathrm{Zr}_{20} \mathrm{Ti}_{20}$ and $\mathrm{Cu}_{55} \mathrm{Zr}_{16} \mathrm{Ti}_{29}$ metallic glass shown at $303 \mathrm{~K}$ in the $r$ region of 1-20 $\AA$. The inset shows $G(r)$ 's in the $r$ region of 2.2$3.7 \AA$ together with corresponding X-ray scattering weights $w_{i j}$ of interatomic bond lengths between a pair of atoms.

For the two glasses, $G(r)$ patterns show a pronounced and broad first peak followed by damping oscillations typical for highly disordered materials. By comparing the alloys $G(r)$ 's, the most evident difference can be seen in position and amplitude of the first $G(r)$ peak and in dephasing of oscillations (visible above $\sim 14.82 \AA$ ).

$\mathrm{Cu}_{60} \mathrm{Zr}_{20} \mathrm{Ti}_{20}$ has the first $G(r)$ peak maximum located at $2.7146 \AA$ and $\mathrm{Cu}_{55} \mathrm{Zr}_{16} \mathrm{Ti}_{29}$ at $2.7071 \AA$ (the inset in Fig. 4). Position, amplitude and shape of the first peak is a result of the distribution of atoms within the first atomic coordination shell; the distribution can be represented by individual atomic pairs, where bond lengths between the atomic pairs are sums of their nominal atomic radii [32] and their significance corresponds to the particular atomic pair X- 
ray scattering ability represented by X-ray scattering weights $w_{i j}$. As it can be seen, the first $G(r)$ peak is mainly formed by the $\mathrm{Cu}-\mathrm{Cu}, \mathrm{Cu}-\mathrm{Ti}$ and $\mathrm{Cu}-\mathrm{Zr}$ atomic pairs, while the peak asymmetry visible on its right side is caused by the $\mathrm{Zr}-\mathrm{Ti}$ and $\mathrm{Zr}-\mathrm{Zr}$ atomic pairs. Larger amplitude of the peak for $\mathrm{Cu}_{60} \mathrm{Zr}_{20} \mathrm{Ti}_{20}$ compared to $\mathrm{Cu}_{55} \mathrm{Zr}_{16} \mathrm{Ti}_{29}$ can be explained by larger $w_{i j}$ for the $\mathrm{Cu}-\mathrm{Cu}$ and $\mathrm{Cu}-\mathrm{Zr}$ atomic pairs and by narrower distribution of the $\mathrm{Cu}-\mathrm{Ti}$ atomic pairs

With increased temperature, the mean atomic neighbours' distances of both glassy alloys expand. The expansion is represented by a progressive shift of $G(r)$ peaks with temperature to the right - towards longer distances. In order to quantify thermal expansion of each $G(r)$ peak position, we determined position of its centre of mass $\left(C_{T}\right)$ and normalized it to the value at 303 $\mathrm{K}$ (parameter $C_{T} / C_{303}$ ). In order to quantify thermal modification of the degree of ordering of the atomic structure, we determined the integral area $\left(I_{T}\right)$ under each $G(r)$ peak, which was similarly normalized to the value at $303 \mathrm{~K}$ (parameter $I_{T} / I_{303}$ ). To get a better overview of the alloys' behaviour, in our calculation of $C_{T} / C_{303}$ and $I_{T} / I_{303}$ we included only the positive part of $G(r)$ peaks $\left(\rho(r)>\rho_{0}\right.$, Fig. 5).

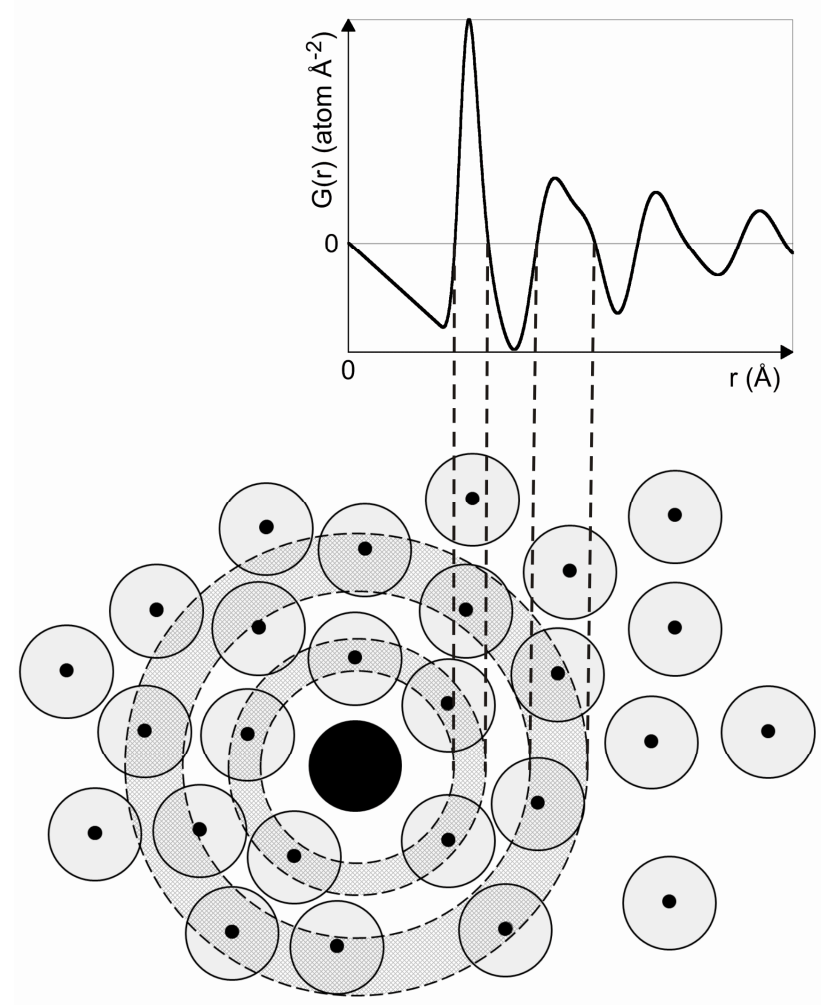

Fig. 5. Principle of $G(r)$ construction. The black circle represents a central atom, the grey circles represent surrounding atoms. The dashed belts define regions, where $G(r)$ is more than zero $\left(\rho(r)>\rho_{0}\right)$. The scheme was drawn according to [33]. 
Fig. 6 illustrates changes of $C_{T} / C_{303}$ for the I., II. III. and IV. $G(r)$ peak as a function of temperature.

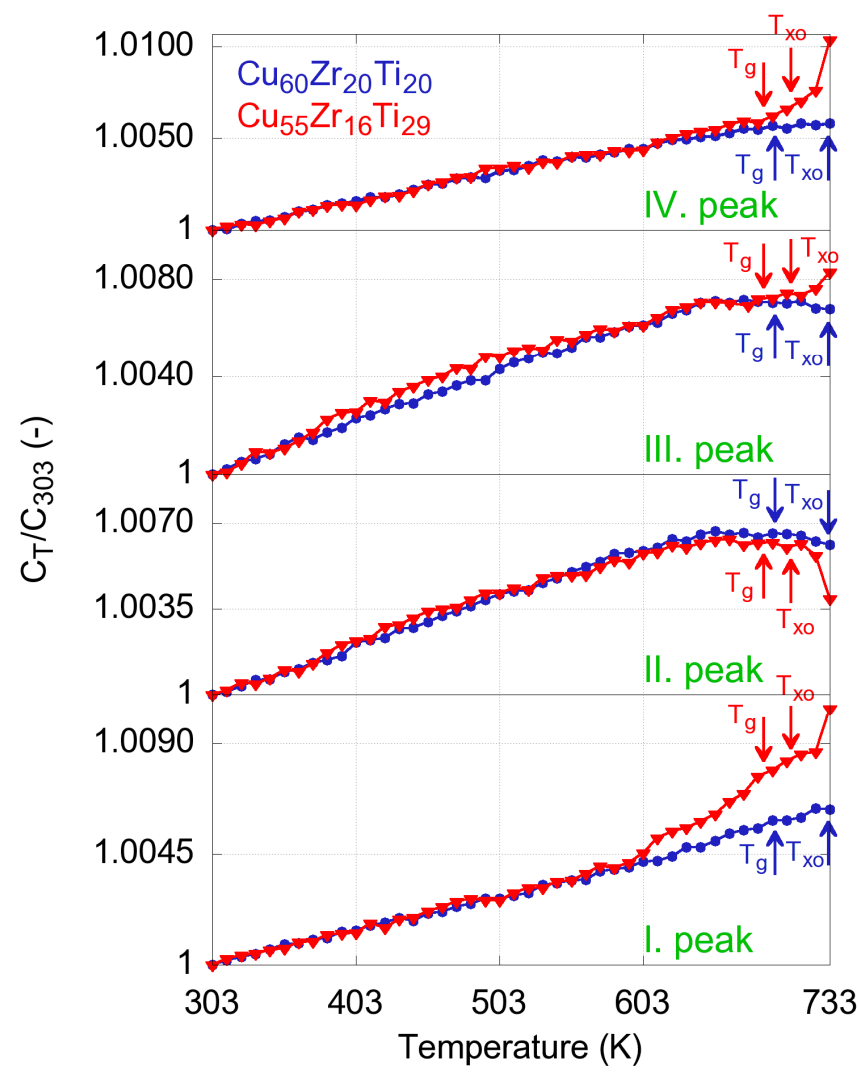

Fig. 6. (Colour online) Centre of mass relative positions $\left(C_{T} / C_{303}\right)$ for the I.-IV. $G(r)$ peak of $\mathrm{Cu}_{60} \mathrm{Zr}_{20} \mathrm{Ti}_{20}$ and $\mathrm{Cu}_{55} \mathrm{Zr}_{16} \mathrm{Ti}_{29}$ metallic glass during the annealing process (shown up to $733 \mathrm{~K}$ ). The full lines are guides for the eyes. Absolute positions of the centre of mass for $\mathrm{Cu}_{60} \mathrm{Zr}_{20} \mathrm{Ti}_{20}$ at $303 \mathrm{~K}: C_{303}$ I.-IV.=2.7452 $\AA$, $4.8197 \AA, 6.9943 \AA$ and $9.2877 \AA$. Absolute positions of the centre of mass for $\mathrm{Cu}_{55} \mathrm{Zr}_{16} \mathrm{Ti}_{29}$ at $303 \mathrm{~K}: C_{303}$ I.-IV.=2.7431 ̊, $4.8223 \AA$, $7.0019 \AA$ And $9.3035 \AA$.

From the figure it follows: $C_{T} / C_{303}$ between $303-603 \mathrm{~K}$ increases more or less linearly and for both alloys almost identically. The average increase slope is $1.456 \times 10^{-5} \mathrm{~K}^{-1} ; 1.94 \times 10^{-5} \mathrm{~K}^{-1}$, $2.039 \times 10^{-5} \mathrm{~K}^{-1}$ and $1.461 \times 10^{-5} \mathrm{~K}^{-1}$ for the I., II., III. and IV. peak, respectively. Above $603 \mathrm{~K}$ the modification of $C_{T} / C_{303}$ is different: the distinction is observed not only between the glasses, but also between $G(r)$ peaks taken from the same alloy. In particular, in the case of $\mathrm{Cu}_{55} \mathrm{Zr}_{16} \mathrm{Ti}_{29}$ glass, for the I. peak $C_{T} / C_{303}$ parameter rapidly increases and compared to other $G(r)$ peaks and all $G(r)$ peaks of $\mathrm{Cu}_{60} \mathrm{Zr}_{20} \mathrm{Ti}_{20}$ the increase is much steeper. Hence, the mean nearest atomic 
neighbour distance shows above $603 \mathrm{~K}$ much higher sensitivity to the atomic thermal motion than distances of other mean atomic neighbours. For distances of the II. and the III. mean atomic neighbour in the case of both glasses one can see above $653 \mathrm{~K}$ suppression of their sensitivity to the atomic thermal motion. In general, thermal expansion of our glassy systems viewed from the local atomic structure perspective is highly anharmonic - comparison of $C_{T} / C_{303}$ courses for the I.-IV. mean atomic neighbour especially between $603-653 \mathrm{~K}$ and $T_{x o}$. The effect of this altering thermal expansion and compression is more pronounced for the $\mathrm{Cu}_{55} \mathrm{Zr}_{16} \mathrm{Ti}_{29}$ system than for the $\mathrm{Cu}_{60} \mathrm{Zr}_{20} \mathrm{Ti}_{20}$ system. Thus, up to $10 \AA$ near $T_{x o}$ the largest modification of $C_{T} / C_{303}$ can be observed for the mean nearest atomic neighbour $\left(C_{T x 0} / C_{303}=1.008268, \mathrm{Cu}_{55} \mathrm{Zr}_{16} \mathrm{Ti}_{29}\right)$ and the smallest modification of $C_{T} / C_{303}$ can be observed for the IV. mean atomic neighbour $\left(C_{T x o} / C_{303}=1.005717, \mathrm{Cu}_{60} \mathrm{Zr}_{20} \mathrm{Ti}_{20}\right)$. Between 10-20 $\mathrm{\AA}$, the V. mean and the following mean atomic neighbours show similar behaviour as the IV. mean atomic neighbour - they shift towards longer distances and the shift is more pronounced (as below $10 \AA$ ) for $\mathrm{Cu}_{55} \mathrm{Zr}_{16} \operatorname{Ti}_{29}$.

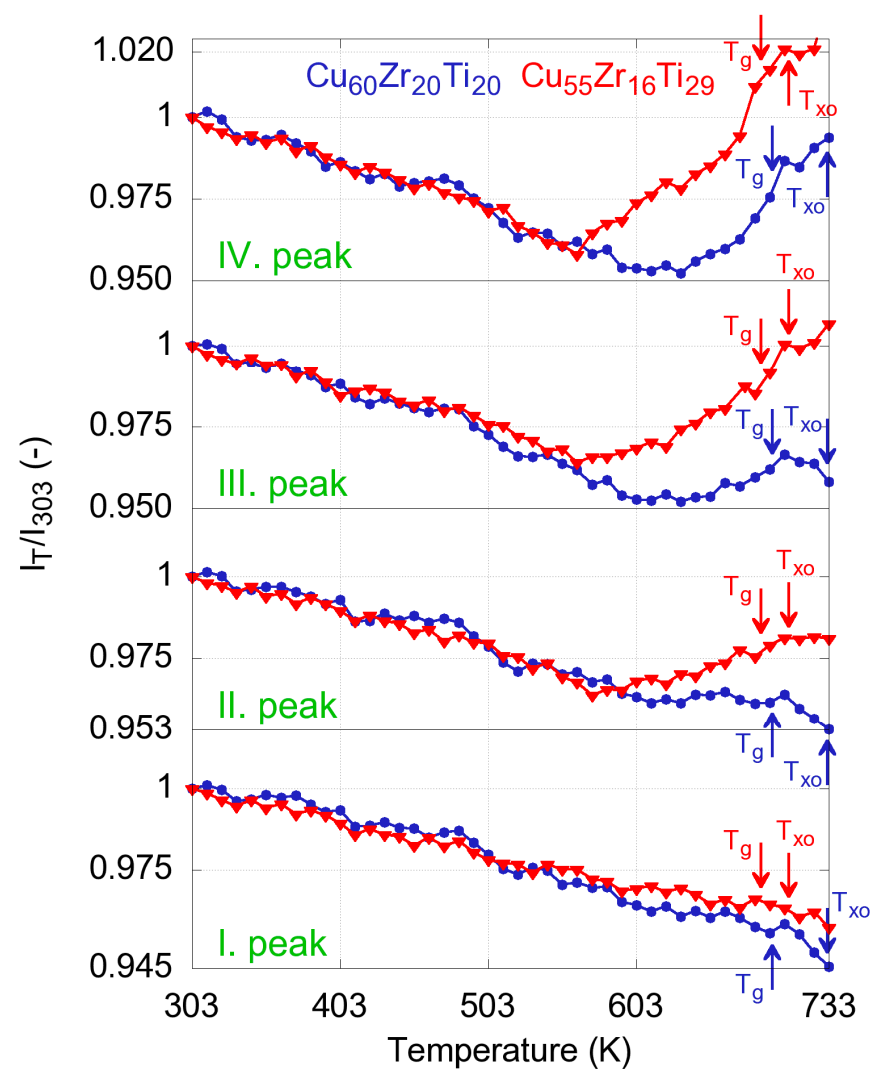

Fig. 7. (Colour online) Relative integral areas $\left(I_{T} / I_{303}\right)$ for the I.-IV. $G(r)$ peak of $\mathrm{Cu}_{60} \mathrm{Zr}_{20} \mathrm{Ti}_{20}$ and $\mathrm{Cu}_{55} \mathrm{Zr}_{16} \mathrm{Ti}_{29}$ metallic glass during the annealing process (shown up to $733 \mathrm{~K}$ ). The full lines are guides for the eyes. Absolute integral areas for $\mathrm{Cu}_{60} \mathrm{Zr}_{20} \mathrm{Ti}_{20}$ at $303 \mathrm{~K}: I_{303}$ I.-IV.=1.992 atom $\AA^{-1}, 1.093$ atom $\AA^{-1}$, 
0.691 atom $\AA^{-1}$ and 0.429 atom $\AA^{-1}$. Absolute integral areas for $\mathrm{Cu}_{55} \mathrm{Zr}_{16} \mathrm{Ti}_{29}$ at $303 \mathrm{~K}: I_{303} \mathrm{I}$-IV.=1.927 atom $\AA^{-1}, 1.073$ atom $\AA^{-1}, 0.672$ atom $\AA^{-1}$ and 0.42 atom $\AA^{-1}$.

To show modification of degree of ordering of the metallic glasses' atomic structure during the annealing, we analysed relative change of integral areas $\left(I_{T} / I_{303}\right)$ of $G(r)$ peaks with temperature. Fig. 7 shows temperature dependence of $I_{T} / I_{303}$ for the I., II., III. and IV. $G(r)$ peak here the situation is opposite compared to $C_{T} / C_{303}$ courses. With elevated temperature atoms located in the atomic coordination shells gain energy resulting in increased oscillations around their mean positions. Increased amplitudes of the oscillations also imply that atoms in the atomic coordination shells become less ordered, what is initially demonstrated by a more or less linear decreasing trend of $I_{T} / I_{303}$ with temperature. However, in the case of $\mathrm{Cu}_{55} \mathrm{Zr}_{16} \mathrm{Ti}_{29}$, the decreasing tendency of $I_{T} / I_{303}$ for the higher atomic coordination shells disappears (from the II. $G(r)$ peak) and above $563-573 \mathrm{~K}$ one can observe the increase of $I_{T} / I_{303}$. A similar effect, but less pronounced can be observed above $633 \mathrm{~K}$ for $\mathrm{Cu}_{60} \mathrm{Zr}_{20} \mathrm{Ti}_{20}$ also from the II. $G(r)$ peak. The rising tendency of $I_{T} / I_{303}$ can be explained by a better ordering of atoms in the atomic coordination shells and/or by migration of atoms from nearby regions to the corresponding atomic coordination shells. Hence, as it is evident from Fig. 7, a larger trend to increase the degree of ordering of its atomic structure (up to $10 \AA$ ) shows $\mathrm{Cu}_{55} \mathrm{Zr}_{16} \mathrm{Ti}_{29}$ and the trend is more significant for both glasses towards more distant atomic coordination shells. Between 10-20 $\mathrm{A}$, the V. and the following atomic coordination shells show similar behaviour as the IV. atomic coordination shell and the ordering increase is more significant (as below $10 \AA$ ) for $\mathrm{Cu}_{55} \mathrm{Zr}_{16} \mathrm{Ti}_{29}$.

According to the precedent real space analysis it can be summarized, that the glasses exhibit a change of their behaviour upon elevated temperature (especially growth of the degree of ordering their atomic structure); the change was not detected by DSC. The temperatures corresponding to the change in the alloys' behaviour reflect a beginning of the thermally activated structural relaxation of the investigated amorphous glassy systems. Generally, the mechanism(s) by which structural relaxation occurs in glasses is through the annihilation of defects or free volume, or recombination of the defects of opposing character, or by changes in both topological and compositional short range order [34]. 
In Fig. 8 we summarized the influence of the annealing on the atomic structure of the metallic glasses near the crystallization (near $T_{x o}$ ) for the I. - VIII. mean atomic neighbour (or the atomic coordination shell; $r$ up to $20 \AA$ ).

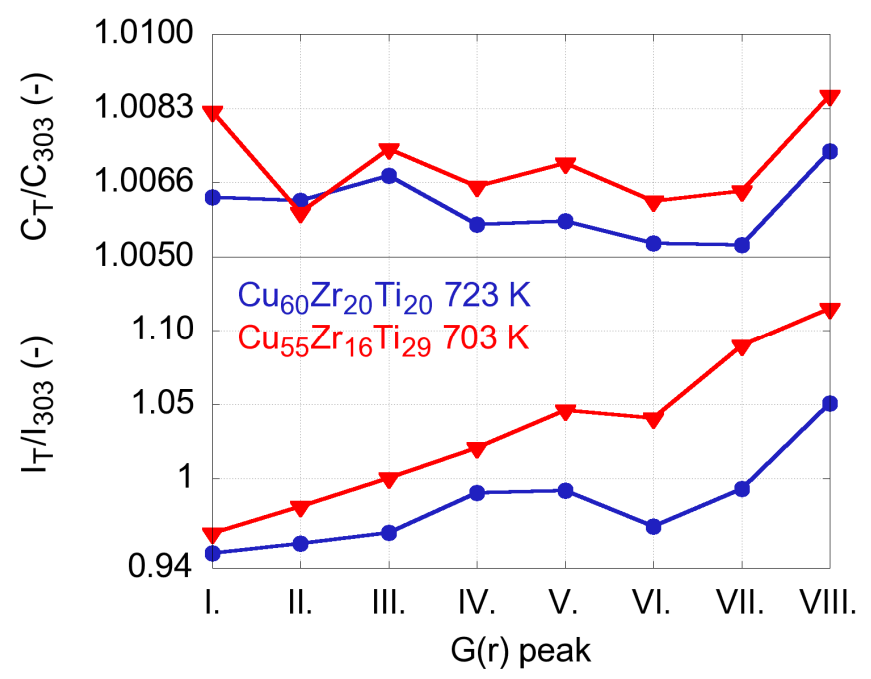

Fig. 8. (Colour online) Centre of mass relative positions $\left(C_{T} / C_{303}\right)$ and relative integral areas $\left(I_{T} / I_{303}\right)$ for the I.-VIII. $G(r)$ peak of $\mathrm{Cu}_{60} \mathrm{Zr}_{20} \mathrm{Ti}_{20}$ and $\mathrm{Cu}_{55} \mathrm{Zr}_{16} \mathrm{Ti}_{29}$ metallic glass near their corresponding $T_{x o}$. The full lines are guides for the eyes.

As it is clear from the figure, all mean atomic neighbours shift towards longer distances and generally larger thermal expansion $\left(C_{T} / C_{303}\right)$ of the mean atomic neighbours' distances exhibits $\mathrm{Cu}_{55} \mathrm{Zr}_{16} \mathrm{Ti}_{29}$ - the only exception seems to be the II. mean atomic neighbour. The courses of $C_{T} / C_{303}$ for both glasses similarly oscillate from the III. $G(r)$ peak and exhibit a slightly decreasing tendency between the III. - VII. mean atomic neighbour. The largest thermal expansion can be observed for the VIII. mean atomic neighbour $\left(C_{T x 0} / C_{303}=1.00737\right.$, $\left.\mathrm{Cu}_{60} \mathrm{Zr}_{20} \mathrm{Ti}_{20} ; \quad C_{T x 0} / C_{303}=1.00862, \quad \mathrm{Cu}_{55} \mathrm{Zr}_{16} \mathrm{Ti}_{29}\right)$ and the smallest one for the II. $\left(C_{T x o} / C_{303}=1.005997, \mathrm{Cu}_{55} \mathrm{Zr}_{16} \mathrm{Ti}_{29}\right)$ and the VII. mean atomic neighbour $\left(C_{T x 0} / C_{303}=1.005259\right.$, $\left.\mathrm{Cu}_{60} \mathrm{Zr}_{20} \mathrm{Ti}_{20}\right)$. Relative changes of integral areas $\left(I_{T} / I_{303}\right)$ of $G(r)$ peaks clearly show that increase of the degree of ordering of the atomic structure (better ordering of atoms) is essentially evident only for $\mathrm{Cu}_{55} \mathrm{Zr}_{16} \mathrm{Ti}_{29}$; the degree increases more or less continuously towards higher $r$ for the III.

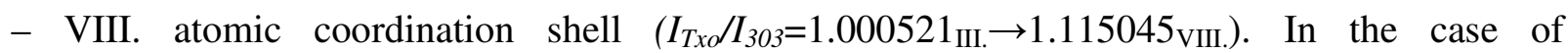
$\mathrm{Cu}_{60} \mathrm{Zr}_{20} \mathrm{Ti}_{20}$, between the I. - VII. atomic coordination shell $I_{T} / I_{303}$ parameter exhibits a gently rising oscillating tendency, and only for the IV., V. and VII. atomic coordination shell it 
approaches a value close to unity. Thus for $\mathrm{Cu}_{60} \mathrm{Zr}_{20} \mathrm{Ti}_{20}$ it can be alleged, that the metallic glass contrary to $\mathrm{Cu}_{55} \mathrm{Zr}_{16} \mathrm{Ti}_{29}$ decreases the degree of ordering of its atomic structure as a result of the annealing process; the only exception is the VIII. atomic coordination shell $\left(I_{T x 0} / I_{303}=1.05067\right)$.

\section{Conclusions}

Our investigation proved different atomic structure and behaviour of $\mathrm{Cu}_{60} \mathrm{Zr}_{20} \mathrm{Ti}_{20}$ and $\mathrm{Cu}_{55} \mathrm{Zr}_{16} \mathrm{Ti}_{29}$ metallic glass in the annealing process before the crystallization. Both glasses initially exhibit with elevated temperature continuous short and middle range order thermal expansion and an overall decline of the atomic structure ordering. After reaching a temperature, which can be slightly different for every mean atomic neighbour (or every atomic coordination shell), a change in behaviour of the glasses (which was detected only by XRD and was not detected by DSC) can be observed: the glasses vary the thermal expansion rate of most of the mean atomic neighbours' distances and show a tendency to increase the degree of ordering of their atomic structure. The increase of the atomic ordering can be explained by the better ordering of atoms in the atomic coordination shells and/or by migration of atoms from nearby regions to the corresponding atomic coordination shells. The temperatures corresponding to the change in the metallic alloys' behaviour reflect a beginning of the thermally activated structural relaxation. In general, thermal expansion of our glassy systems viewed from the local atomic structure perspective is highly anharmonic.

The modification of the atomic structure is before the crystallization more significant for $\mathrm{Cu}_{55} \mathrm{Zr}_{16} \mathrm{Ti}_{29}$. Therefore, as a result of the glasses' different behaviour in the annealing, $\mathrm{Cu}_{55} \mathrm{Zr}_{16} \mathrm{Ti}_{29}$ generally shows near the crystallization temperature larger relative elongation of the mean atomic neighbours' distances (larger thermal expansion) than $\mathrm{Cu}_{60} \mathrm{Zr}_{20} \mathrm{Ti}_{20}$ and increase of the degree of ordering of the atomic structure if compared with the initial as-prepared state at the beginning of the experiment; the increase is more pronounced towards higher $r$ (middle range order). $\mathrm{Cu}_{60} \mathrm{Zr}_{20} \mathrm{Ti}_{20}$ decreases the degree of ordering of its atomic structure as a result of the annealing process. 


\section{Acknowledgements}

The authors thank Deutsches Elektronen-Synchrotron (DESY) for provision of the synchrotron radiation facility in using the beamline BW5, proposal No. I-20110689. The research leading to these results has received funding from the European Community's Seventh Framework Programme (FP7/2007-2013) under grant agreement No. 312284.

K.S. and D.B. are indebted to the Slovak Grant Agency for Science for financial support (grant No. 2/0128/13).

A.P. is grateful to the Scientific Grant Agency of the Ministry of Education, Science, Research and Sport of the Slovak Republic and the Slovak Academy of Sciences (VEGA Project No. 51/0218/13) for the financial support of this work. 


\section{References}

[1] J. Eckert, J. Das, K.B. Kim, F. Baier, M.B. Tang, W.H. Wang, Z.F. Zhang, Intermetallics 14 (2006) 876-881.

[2] K. Asami, H. Habazaki, A. Inoue, K. Hashimoto, Mater. Sci. Forum 502 (2005) 225-230.

[3] K. Asami, C.L. Qin, T. Zhang, A. Inoue, Mater. Sci. Eng. A 375-377 (2004) 235-239.

[4] S. Pauly, J. Das, N. Mattern, D.H. Kim, J. Eckert, Intermetallics 17 (2009) 453-462.

[5] D.V. Louzguine, A. Inoue, J. Mater. Res. 17 (2002) 2112-2120.

[6] M. Kasai, J. Saida, M. Matsushita, T. Osuna, E. Matsubara, A. Inoue, J. Phys.: Condens. Matter 14 (2002) 13867.

[7] Q.P. Cao, Y.H. Zhou, A. Horsewell, J.Z. Jiang, J. Phys.: Condens. Matter 15 (2003) 8703.

[8] A. Concustell, A. Revesz, S. Suriňach, L.K. Varga, G. Heunen, M.D. Baró, J. Mater. Res. 19 (2004) 505.

[9] Y. Pan, Y. Zeng., L. Jing, L. Zhang, J. Pi, Materials and Design 55 (2014) 773-777.

[10] Q. Wang, J. Qiang, Y. Wang, J. Xia, C. Dong, J. Non-Cryst. Solids 353 (2007) 3425-3428.

[11] C.L. Dai, H. Guo, Y. Li, J. Xu, J. Non-Cryst. Solids 354 (2008) 3659-3665.

[12] A.H. Cai, X. Xiong, Y. Liu, W.K. An, G.J. Zhou, Y. Luo, T.L. Li, X.S. Li, J. Non-Cryst. Solids 379 (2013) 1-6.

[13] A.H. Cai, X. Xiong, Y. Liu, W.K. An, G.J. Zhou, Y. Luo, T.L. Li, X.S. Li, Sci. ChinaPhys. Mech. Astron. 56 (2013) 1606-1610.

[14] A.J. Kailath, S. Mandal, J. Alloys Compd. 537 (2012) 275-279.

[15] T. Naoi, H. Nishikawa, T. Takemoto, H. Abe, M. Fukuhara, A. Inoue, Quarterly J. Japan Welding Soc. 29 (2011) 147-150.

[16] H. Abe, K. Sato, H. Nishikawa, T. Takemoto, M. Fukuhara, A. Inoue, Mater. Trans. 50 (2009) 1255-1258.

[17] J. Basu, B.S. Murty, S. Ranganathan, J. Alloys Compd. 465 (2008) 163-172.

[18] R. Bouchard, D. Hupfeld, T. Lippmann, J. Neuefeind, H.-B. Neumann, H.F. Poulsen, U. Rutt, T. Schmidt, J.R. Schneider, J. Sussenbach, M. von Zimmermann, J. Synchrotron Radiat. 5 (1998) 90-99.

[19] L.B. Skinner, C.J. Benmore, J.B. Parise, Nucl. Instrum. Methods Phys. Res. A 662 (2012) 61-70.

[20] F.M. Reza, An Introduction to Information Theory, Dover Publications, New York, 1994. 
[21] J. Bednarcik, J. Gamcova, H.P. Liermann, New heating/cooling stage available to users at P02.1, DESY Annual Report (2012) 1-2.

[22] A.P. Hammersley, S.O. Svensson, M. Hanfland, A.N. Fitch, D. Häusetmann, High Press. Res. 14 (1996) 235-248.

[23] Y. Waseda, The Structure of Non-Crystalline Materials, McGraw-Hill, New York, 1980.

[24] B.J. Thijsse, J. Appl. Crystallogr. 17 (1984) 61-76.

[25] B.E. Warren, X-ray Diffraction, Dover Publications, New York, 1990.

[26] T. Egami, S.J.L. Billinge, Underneath the Bragg Peaks: Structural Analysis of Complex Materials, Pergamon, Oxford, 2003.

[27] X. Qiu, J.W. Thompson, S.J.L. Billinge, J. Appl. Cryst. 37 (2004) 678-678.

[28] T.E. Faber, J.M. Ziman, Phil. Mag. 11 (1965) 153-173.

[29] J. Zhou, X. Bian, W. Wang, X. Xue, S. Wang, Y. Zhao, K. Yin, Mater. Lett. 58 (2004) $2559-2563$.

[30] E. Matubara, K. Harada, Y. Wasada, H.S. Chen, A. Inoue, J. Mater. Sci. 23 (1988) 753.

[31] W. Hoyer, R. Jodicke, J. Non-Cryst. Solids 192 and 193 (1995) 102.

[32] B. Ravel, M. Newville, J. Synchrotron Rad. 12 (2005) 537-541.

[33] C. Janot, Quasicrystals, Oxford University Press, New York, 1997.

[34] C. Suryanarayana, A. Inoue, Bulk Metallic Glasses, CRC Press, Boca Raton, 2011. 